\begin{abstract}
ARTIGO
* $O$ texto a seguir corresponde ba. sicamente a uma primeira versáo do projeto de tese de Mestrado em Ciência Politica - "Reformas e Reformismo: Democracia Progressiva e Políticas Sociais"- apresentado pelo autor ao IUPERJ (Inst. Universitário de Pesquisas do Rio de Janeiro/Faculdades Candido Mendes), acrescido de uma "Introdução" escrita para fins desta publi cação.
\end{abstract}

* Departamento de Administraf̧äo e Planejamento, ENSP/FIOCRUZ

\section{Reformas e Reformismo: "Democracia Progressiva" e Políticas Sociais (ou "Para uma teoria política da Reforma Sanitária")*}

\section{Jaime A. Oliveira *}

Na introdução deste artigo, o autor parte de uma preocupação como debate atual em torno do processo de tentativa de inovação política setorial que vem sendo designado entre nós pela expressão "Reforma Sanitária". Chama a atenf̧ão para os diferentes sentidos em que, a seu ver, esta expressão tem sido utilizada no Brasil. E se dispõe a deter-se, particularmente, em um destes sentidos: o que se aproxima da formulação italiana de mesmo nome (a "Riforma Sanitaria").

Esta discussão o leva, no corpo do artigo propriamente dito, a tratar, centralmente, da relação entre as caracteristicas assumidas pela ordenação política liberal contemporânea e a estratégia gramsci-togliattiana de transição no socialismo, no que tange ao tema das chamadas "Politicas Públicas" $e$, mais particularmente, das "Políticas Sociais". $O$ artigo termina com um esboço inicial de um projeto de investigação comparativa nesta área.

11111111111111111111111111111111111111111111111111111111

\section{INTRODUÇÃO: O QUE É "REFORMA SANITÁRIA"?}

\section{1) Por uma Teoria Politica da Reforma Sanitária.}

60 Oliveira, Jaime A. - Interesses Sociais e Mecanismos de representação: a Política de Saúde no Brasil pós-64, ENSP/Secretaria de Ciència e Tecnologia - MS, 1983 , mimeo, 174 pgs.

62 Oliveira, Jaime A. e Sónic $M$. F. Teixeira - (In) Previdència Social: 60 anos de História da Previdência no Brasil, Rio, Edit. Vo. zes, 1986.

\footnotetext{
* Embora este processo nẽo tenha transcorrido de forma tāo mecanica quanto, com freqüencia, se cos.
}

Como assinalamos em outros lugares, ${ }^{60,62}$ a literatura, já numericamente significativa, em torno do tema da política de saúde no Brasil pós-64, nos sugere a possibilidade de recortar a história desta questão em, "grosso modo", dois grandes períodos:

19) O que vai de meados dos anos 60 a meados dos anos 70. E que é marcado, como se sabe, pela progressiva constituição, ao longo do período mais "fechado" do regime militar, de um dado modelo de organização do sistema de atenção à saúde. O qual. em síntese e objetivamente, caminhou na direção da lógica do privilegiamento de interesses econômicos - corporativos do empresariado privado que atua nesta área;*

29) $O$ período que se seque a meados dos anos 70 , no Cadernos de Saúde Pública, R.J., 4(3): 360-387, out/dez, 1987. 
qual instala-se, progressivamente, o que designamos em outra ocasião * como uma "crise político-financeira" do modelo assistencial estabelecido nos anos anteriores. "Crise" esta que não passa, na verdade, de uma expressão setorial da situação mais abrangente, de crise - simultaneamente econômica e política, "de legitimação" e "fiscal" - que o regime autoritário atravessou, naqueles anos de fim do anterior período de crescimento acelerado da economia, e de início do chamado processo de "abertura" política.

Como conseqüência deste quadro, este segundo período foi marcado também pelo surgimento de um conjunto de hoje conhecidas proposições, voltadas todas "grosso modo", para a idéia do controle, reforma, e racionalização do modelo assistencial anteriormente estabelecido.

Mas, em terceira característica central deste período - que também tem sido assinalada pela literatura sobre o tema - corresponde ao fato de que, praticamente todas estas proposições, tiveram que enfrentar fortes dificuldades políticas de viabilização (nascidas, em síntese, dos interesses empresariais setoriais privados beneficiários do "status quo" anterior na área, e das articulaçōes que estes setores conseguiram desenvolver, ao interior da burocracia governamental e das "máquinas políticas" aí influentes). E estas dificuldades de viabilização, quando não levaram ao fracasso total das proposições de controle e reforma apresentadas ao período, produziram pelo menos fortes limitações no impacto e nas conseqüências destas propostas.

O que queremos assinalar, em síntese, com esta rápida revisão das formulações presentes na literatura sobre o tema em tela, é o fato de que, como resultado de um rico processo de discussão e análise coletivos, foi possível, nos últimos anos, àqueles que se dedicam ao estudo deste problema, extrair, de uma prática igualmente rica, aí em curso no mesmo período, uma teorização sóbre esta prática. Sobre suas possibilidades (abertas pela crise do pós-74, por oposição à cristalizada situação anterior); e sobre suas limitações (dadas pelas resistências dos interesses econômicocorporativos empresariais; pelos determinantes "fiscais" da crise; e pelos limites de um projeto de legitimação governamental).

Mas, a partir, principalmente, do ano passado (1986), e tendo "grosso modo" como marco de referência a VIII Conferência Nacional de Saúde, vem se desenhando algo que, a nosso ver, pode vir a constituir-se como um novo corte na história recente da questão de que estamos tratando.

Quero me referir ao debate crescente, que vem se desenvolvendo desde então, em torno ao tema da chamada Cadernos de Saúde Pública, R.J., 4(3): 360-387, out/dez, 1987. tuma imaginar. A respeito, ver Oliveira (1983), op. cit.

* * Ibid. 
"Reforma Sanitária". Expressão que, por isso mesmo, vem se tornando rotineira nesta área.

O sentido atribuído ao termo, ultimamente, entre nós, nem sempre é claro ou preciso. $\mathrm{E}$, na verdade, o que se tem feito, com freqüência, é apenas utilizar uma nova e altissonante expressão - "Reforma Sanitária" - simplesmente para rebatizar proposições já há muito em curso nesta área (particularmente a idéia das "Ações Integradas de Saúde", ou dos "Distritos Sanitários"). Proposições que, em sintese, seguem uma linha de continuidade com o que designamos acima como um segundo período (pós-74) da história recente da Política de Saúde entre nós.

Mas pode-se depreender, por outro lado, a partir de alguns textos e situações em que esta expressão tem sido utilizada (por exemplo, a partir da experiência viva da VIII Conferência Nacional de Saúde, e de alguns pontos do seu Relatório Final), a aspiração, ainda que por vezes vaga e imprecisa, por um avanço em relação ao tipo de proposições em vigor nos últimos anos. E não sua mera continuidade.

O que estamos querendo frisar, é que está em curso talvez desde os debates preparatórios da VIII Conferência - aquilo que se nos apresenta como um movimento potencialmente inovador no âmbito da prática política no campo da saúde entre nós. $\mathrm{E}$, com isso, chamar a atenção para algo que nos parece importante (como foi no passado recente), para o desenvolvimento desta prática, ou seja: a sua teorização.

Em outros termos, o que estamos querendo frisar é a idéia de que, a nosso ver, vem se colocando, crescentemente, a necessidade de procurar desenvolver, para o movimento potencialmente inovador que se esboça hoje no âmbito da política de saúde entre nós, um esforço de teorização, que corresponda, para este (talvez) novo período, a algo como aquele esforço que foi possivel desenvolver para o período anterior.

Como da outra vez, no entanto, esta só pode ser uma tarefa essencialmente coletiva. Que resulte do debate (polí. tico-teórico) entre os interessados na questão. E o projeto de investigação que se segue procura ser apenas uma co. laboração neste sentido.

\section{2) "Reforma Sanitária" e Transição}

Antes de entrar no projeto ora proposto, queremos explicitar algo que é a ele subjacente, e que resulta do que foi exposto no item anterior desta introdução.

A nosso ver a discussão sobre a Política de Saúde no 
Brasil pós-74, sintetizada acima, apontava, em última análise, como vimos, para a idéia da possibilidade, aí estabelecida, de promover algum grau de mudanças frente ao quadro anterior, nos marcos (e em função de) uma crise fiscal e de legitimidade do regime então vigente. Crise esta que abria certo espaço objetivo de possibilidades para o enfrentamento da lógica anteriormente dominante nesta área, que era a de um puro e aberto privilegiamento de interes. ses econômico-corporativos empresariais setoriais.

Esta questão, como se sabe, não está ainda resolvida. Ou seja. persiste a tensão entre as tendências racionalizadoras do modelo assistencial dominante, e as resistências empresariais privadas e intraburocráticas a estas propostas.

Há, portanto, muito o que fazer, ainda, nesta direção. Isto é, na direção dos esforços racionalizadores, na linha da resolução da crise fiscal e de legitimidade. E setores progressistas da burocracia governamental da área trabalham, por isso mesmo, nesta direção (e, a meu ver, devem continuar a fazê-lo).

Mas, no meu entendimento, a idéia de "Reforma Sanitária" pode ter um significado inovador frente a este quadro, na medida em que esta proposição aponte numa direção que se situe, (e hoje pode situar-se) para além daquelas preocupações (e de suas autolimitações). Ou seja, se situe para além dos esforços de resolução de uma crise de legitimidade e fiscal do Estado. E, portanto, no limite, para além dos esforços de auto-reprodução deste Estado, e das condições econômico-sociais e políticas que ele ajuda a sustentar.

Assim, se o periodo ainda em curso no âmbito da Política de Saúde no Brasil tem sido marcado por uma tensão, entre, por um lado, mesquinhos interesses economico-corporativos enraizados nesta área, e, por outro, esforços ra. cionalizadores, que compōem, em última análise, um projeto de recuperaçâo da eficácia político-ideológica das Políticas Sociais enquanto instrumento de hegemonia; o período que hoje se esboça deveria, a meu ver - se quer configurar-se como algo efetivamente novo - ser marcado por uma tensão entre projetos de hegemonia alternativos.

Para quem concebe a luta pela hegemonia desde uma dada visão do movimento das coisas, na qual a idéia de "superação" significa incorporação e elevação a um nivel superior, não há por que desqualificar o momento anterior do processo de que estamos tratando aqui, nem anatemizar os que ainda lutam dentro dele. Uma vez que é exatamente este esforço que tem aberto espaços para o surgimento do algo novo. 
Mas o novo, nesta área, já está aí. Vivo, pulsando, e precisando compreender-se. Precisando compreender por onde passa, efetivamente a idéia de "avanços" frente às proposições anteriores, que é a sua idéia-força.

O projeto de investigação que é apresentado mais adiante procura situar-se, como se verá, nesta linha de preocupações.

3) Reformas e Reformismo: Reforma e "Riforma" (ou, tentando uma palavra de ordem: "italianizar" a Reforma Sanitâria Brasileira).

Apesar do caráter vago e impreciso com que, freqüentemente, tem sido utilizada entre nós a expressão "Reforma Sanitária", não há dúvida de que o termo tem uma origem determinada. Ele corresponde à tradução literal da expressão que vem designando, há alguns anos, uma experiência de formulação e implementação de Políticas públicas em curso na Itália: a chamada "Riforma Sanitaria". Experiência que se tornou bastante conhecida entre nós nos últimos anos, principalmente a partir da publicação no Brasil de livros de Giovanni Berlinguer; de repetidas vindas deste autor ao Brasil; e da estada de alguns estudiosos brasileiros da área naquele país europeu.

Mas, a meu ver, é possivel identificar pelo menos duas grandes linhas de diferenciação (em boa medida inter-relacionadas) entre os processos que, respectivamente, na Itália e no Brasil, vêm sendo designados pela mesma expressão: "Reforma Sanitária".

A primeira destas diferenças corresponde ao fato de que, na Itália, o processo da "Reforma Sanitária" corres. pondeu, como se sabe, a um movimento "de fora para dentro" em relação ao aparelho de Estado. Ou, se quisermos, "de baixo para cima". Isto é, constituiu-se por uma aglutinação progressiva de diferentes movimentos sociais que já vinham exercendo uma crescente pressão sobre o aparelho do Estado, relativa a diversos temas vinculados à questão da saúde. Pressão esta que, com o tempo no entanto, e ao longo deste processo, foi superando os limites e as barreiras das diferentes reivindicações de caráter corporativo que a compunham (vinculadas aos in teresses específicos dos diferentes movimentos sociais aí envolvidos), para articularse en torno de uma proposição generalizadora: a idéia da "Refoma Sanitária".

Enquanto que, no Brasil, o movimento pela assim chamada "Reforma Sanitária" vem se desenvolvendo, ma- 
joritariamente, como um movimento "de dentro para fora", ou "de cima para baixo".

Ou seja, entre nós, a fórmula "Reforma Sanitária", (com os diferentes sentidos em que esta expressão tem sido empregada aqui) surgiu principalmente a partir de um conjunto de técnicos (ou talvez seja melhor dizer hoje, a partir de diferentes técnicos) que têm em comum um passado de preocupações progressistas, vêm a si mesmos como componentes de um autoproclamado e informal "partido sanitário", e que ocupam hoje, com freqüência, postos e posições significativas ao interior do aparelho de Estado na área.

Mas a segunda, e mais importante, diferença entre os dois "casos" em questão corresponde ao fato de que, por um lado, a idéia da "Reforma Sanitária" surgiu na Itália do imediato pós-guerra, e, portanto, no contexto de um processo de transição de uma ordenação política autoritá. ria (o fascismo) para um regime de natureza liberal-democrática. Logo, ela surgiu do interior de um contexto, neste sentido, análogo ao que vivemos nós hoie.

Mas, por outro lado, no caso italiano, a idéia da " $R e$ forma Sanitária", pelo menos da perspectiva do ator político que a formula em primeiro lugar - o Partido Comunista Italiano - surge como uma idéia que é pensada enquanto parte, simultaneamente, de um outro processo de transição, de mais longo prazo e alcance: a transição para o socialismo. Nos termos em que a tradição gramsci-togliattiana, que informa a atuação daquele partido, concebe a estratégia possivel para que uma tal transição se dê em um contexto político e social como o italiano (isto é, um contexto com características "ocidentais", onde o Estado já adquiriu sua configuração moderna, "ampliada"; onde já se constituiu uma situação de hegemonia burguesa, etc.). Qual seja: a estratégia correspondente ao que Gramsci designava por "Guerra de posiçâo". Noção retomada e desenvolvida por um continuador de sua obra teórica e política (Palmiro Togliatti) no conceito de "Democracia Progressiva", e que encontra eco naquilo que os comunistas italianos contem. porâneos (como, por exemplo, Pietro Ingrao) entendem hoje por "Democracia de Massas".

Logo, a idéia de "Reforma Sanitária" é pensada, na Itália, desde o início, como algo que não se restringia aos limites de um projeto de hegemonia "burgués". Mas sim como algo que visava superá-lo, no sentido dialético rigoroso do termo.

Em outros termos, a idéia de "Reforma Sanitária" é pensada, na Itália, desde o início, como parte de uma estratégia de contra-hegemonia. Onde passam, por isso mes- 
mo, a adquirir importância fundamental, noções como, por exemplo, as de "Democratização do Estado", e de "Consciência Sanitária".

Enquanto isso, no Brasil, como já assinalamos, a expressão "Reforma Sanitária" vem sendo usada, pelo menos muito freqüentemente, com um sentido muito mais restrito. Ou seja, apenas como um novo nome, para rebatizar antigas proposiçōes, constitutivas de um movimento que já dura mais de dez anos, e cuja natureza e limites já comentamos acima.

Já o disse, e repito, que não estou, com isso, querendo desqualificar este movimento. Muito pelo contrário. Uma vez que é ele, inclusive, que cria condições para a emergência de algo novo.

$E$, portanto, também não estou desqualificado ( $\mathrm{e}$ igualmente já o disse antes), o papel daqueles, que, seja pela sua posição institucional atual, seja por legítima opção polí. tica (liberal, social-democrática) considerem que o limite da sua atuação é o demarcado pelo processo de transição que hoje vivemos, e por sua expressão no âmbito da Política de Saúde.

Finalmente, não estou imaginando que se possa desenvolver, a partir do interior do próprio aparelho de Estado, um processo que vise, em última instância, a superação dos seus limites.

Mas sim estou, em primeiro lugar, querendo me dirigir àqueles que, como eu, viram, e continuam vendo, a ordem liberal-democrática como uma (entre nós árdua) conquista no caminho para o socialismo. E que concebem a este como uma superação dialética, e não como uma ne. gação mecânica daquela.

$\mathrm{E}$, em segundo lugar, sugerir a tese de que apenas os movimentos sociais, e seus articuladores no plano supracorporativo - os partidos políticos de esquerda - podem e devem buscar dar à "Reforma Sanitária" brasileira um novo caráter, que transcenda o movimento anterior nesta área, embora incorporando-o (e, nisso, os partidos políticos em especial têm, até aqui, falhado, quando não se mostrado simplesmente omissos).

Nesta direção a Reforma Sanitária não pode ser pensada apenas como meras modificações técnico-administrativas e organizacionais. Mas sim precisa dar posição central a temas como o da Democratização do Estado, e da formulação de um projeto contra-hegemônico (no que a questão da "consciência sanitária", e da ampliação do conceito de "direito à saúde" colocam-se como pontos vitais). Bem como refletir sobre quais são os mecanismos concretos através dos quais o Estado "digere" proposições potencialmente radicais, como o sentido original da expressão "Reforma 
Sanitária" transformando-as em formulações "reformis. tas" no sentido preciso do termo.

\section{1a PARTE: O PROBLEMA}

1) "Guerra de Posição", "Democracia Progressiva", "Democracia de Massas".
1.1. - A ordenação política contemporânea e as estratégias de transição ao socialismo.

Desde a última década do século passado, com as reflexões do "último Engels" sobre o crescimento da socialdemocracia alema $\tilde{a}^{22}, 55$ passou a assumir importância cres. cente no interior do pensamento político de inspiração marxista, o tema das características específicas assumidas pelo Estado capitalista e pela ordenação política contemporâneos, na associação que este tema comporta com a problemática da estratégia revolucionária, de transição para o socialismo, nos contextos a que Gramsci chamaria, mais adiante, de "Ocidentais" 2 ?

Mas, como se sabe, o desenvolvimento desta questão nos anos imediatamente posteriores (da passagem do século) pelos teóricos da social-democracia alemã (como Bernstein ou Kautsky) ${ }^{29,30}$ se deu de forma tal que levou esta corrente de pensamento e ação política a, em última análise, um progressivo afastamento do campo marxista. Afastamento que veio a culminar, em periodos mais recentes, na ruptura explícita de boa parte dos partidos socialdemocratas da II Internacional com os pressupostos teóricos desta matriz de pensamento.

Como também é sabido, este afastamento da socialdemocracia alemã dos pressupostos da teoria política marxista foi assinalado e criticado à época por Lenin ${ }^{40,42}$, com a reafirmação, por parte do autor russo, da natureza de classe do Estado capitalista. mesmo em sua configuração contemporânea. E a conseqüente necessidade de sua "quebra", ou "dissolução" como parte da estratégia de transição para o socialismo, em oposição à estratégia reformista social-democrata, de, em síntese, mera "ocupação" do Estado. Tema que ocupou posição central, como também se sabe. na ruptura de Lenin com a II Internacional, e na criação, a partir daí, dos partidos da III Internacional em diferentes países.

Mas a discussão sobre a especificidade do Estado capitalista contemporâneo - i.e., sobre as formas e mecanismos próprios, particulares, através dos quais ele é "Estado". e ele é "capitalista" ou seja, através dos quais ele é, 
* Podendo-se também, a nosso ver, ainda nos anos 10 , identificar este tema como implicitamente presente na polêmica que ume autora como Rosa Luxemburg sustenta, ao mesmo tempo, contra o reformismo da II Internacional, e con. tra alguns aspectos do pensamento de Lenin (relativos principalmente dे questão do partido, $e$ as caracteriticas que começavam a ser assumidas pela Revoluçāo Russa).

\footnotetext{
* Embora o tema continuasse polêmico ao interior do "Komin. term", através de autores/persona. gens como Dimitrov ou Togliatti, e com base em experiências politicas concretas como as da Guerra Civil Espanhola, e do "Front Po. pulaire" francês.
}

em última instância, um instrumento de dominação e direção da sociedade no rumo de interesses "burgueses" - voltaria a impor-se, pouco mais adiante, no início dos anos 20 , ao interior do campo marxista $4,45,53^{*}$. Desta vez, tendo como móvel o contraste então estabelecido entre, por um lado, a vitória da revolução socialista na Rússia tzarista e, por outro, a derrota de tentativas de mesma natureza na Europa Ocidental. Que veio reenfatizar, de forma dramáti: ca, a importância da discussão sobre a especificidade da ordenação política capitalista moderna, e sua maior resistência à transformação revolucionária.

Como se sabe, esta questão tornou-se central no pensamento político marxista dos anos $20 / 30$, através de autores como Gramsci $11,27,25,26,28,46,66,17$ ou os teóricos da Escola de Frankfurt ${ }^{4}, 13,39$ ou, ainda do chamado "austro-marxismo". Para não falar na reorientação que ela suscita nas proposições estratégicas do próprio Lenin para a III Internacional no início dos anos 20 .

Os 30 anos seguintes, no entanto (até meados da dé. cada de 50) foram marcados por uma relativa paralização, sob Stalin, do debate em torno do tema em questão ${ }^{* 18} 8$. E, a partir daí, por uma tentativa de universalização - acrítica, e, em muitos contextos, imobilizante - da estratégia revolucionária que fora eficiente na Rússia tzarista de 17 (mas derrotada na Europa Ocidental), e que Gramsci desig. nara, por analogia com a estratégia militar, como uma "Guerra de Movimento".

O clima de reatividade do livre debate teórico-político ao interior do campo marxista, que estabelece após Stalin, aliado à persistência das dificuldades impostas à transição para o socialismo no "Ocidente", fará no entanto, ressurgir o nosso tema ao interior do pensamento político marxista contemporâneo, onde ocupa até hoje uma posição-chave. "Redescobre-se", neste sentido os autores dos anos 10, 20 e 30 (como Rosa Luxemburg 4, 45, Gramsci ${ }^{25,26,27}$, Togliatti ${ }^{76,77}$, Dimitrov, os Frankfurtianos, e os austríacos): retorna-se aos "clássicos" buscando indicações aí presentes (embora de forma não sistematizada) sobre o problema; e, a partir desta retomada, desenvolveu-se uma produção relativamente original, expressa, por exemplo, na obra de autores con temporâneos: alemães (como os adeptos da chamada "teoria derivacional", ou Hirsch, ${ }^{33}$ Offe, ${ }^{57,58}$ ou ainda Habermas; ${ }^{31}$ franceses como Althusser, ${ }^{2,3}$ Poulantzas, ${ }^{67}$, 68,69 J. M. Vincent, ${ }^{79}$ ou C. Bucci-Glucksmann; ${ }^{11,12}$ italianos (como Togliatti, ${ }^{76,77}$ Ingrao, ${ }^{36}$ Cerroni, Bobbio, ${ }^{9}$, ${ }^{10}$ ou Napolitano); ${ }^{54}$ suecos (como G. Therborn) ${ }^{74,75}$ etc. 
1.2. - As Noções de "Guerra de Posição" e "Democracia Progressiva", e seus Principais "Interlocutores".

Foi no interior do quadro político e teórico que procuramos sintetizar a seção anterior que, como também se sabe, Gramsci, nos anos 20/30, cunhou e/ou revitalizou noções hoje tornadas célebres, e associadas a seu nome.

Como, por exemplo - retomando indicações mais ou menos implícitas nos "clássicos" do marxismo (em especial Engels e Lenin) - o conceito de "hegemonia". E, a partir deste, a noção de "Estado ampliado", na tentativa de dar conta da modernidade da ordenação política contemporânea. Ou, ainda, a noção que será central neste nosso trabalho - de "guerra de posição" (por contraste com a idéia correlata de "guerra de movimento" 27 enquanto proposta de orientação estratégica para a luta pelo socialismo no contexto que o autor italiano descreve sinteticamente como o "Ocidente". Noção que será retomada e ampliada, no pós. guerra por Togliatti, através do conceito de "Democracia Progressiva $11,30,71,76,77$, conceito este que, por sua vez, está associado àquilo que os comunistas italianos entendem hoje por "Democracia de Massas",36

\subsection{1 - "Democracia Progressiva" e Social-Demo. cracia: a questão da "Quebra" do Estado.}

Mas é preciso frisar, para a seqüência da nossa discussão - e entrando agora num terreno mais polêmico e menos consensual - a idéia de que, a noção gramsci-togliattiana de "guerra de posição"/ "democracia progressiva", se distingue, por um lado, daquilo que Gramsci designava por "guerra de movimento", por outro lado, não pode ser reduzida e identificada à estratégia social-democrata (defendida, como vimos, pela II Internacional desde o inicio do século) de mera "Ocupaçāo" (sem "quebra") do aparelho de Estado capitalista por um partido de extração operária, como via de transição para o socialismo*.

Como já assinalamos, a crítica desta formulação social-democrata é um ponto nodal do pensamento político de Lenin. Para a defesa do qual ele recupera a noção marxiana de "quebra" do Estado enquanto um elemento essencial da transição para o socialismo.

Entendendo-se, em síntese, por "quebra do Estado" a idéia da necessidade de promover modificações estruturais em características básicas e específicas do Estado capitalista (por exemplo, sua tendência à burocratização e centralização), sem o que este não perde sua "natureza de clas$s e$ ", ou seja, mesmo que eventualmente ocupado por atores Cadernos de Saúde Pública, R.J., 4(3):360-387, out/dez, 1987.
anTICO 
- Foge, no entanto, ao ámbito de nosso interesse neste trabalho a complexa discussäo sobre se, $e$ em que medida, o aparelho de Es. tado foi, a partir dai, efetivamente "quebrado" nas experiências do chamado "socialismo real".

* -Marcadas, em síntese, como se sabe, por um quadro de insuficiência de hegemonia burguesa ou - na célebre fómla gramsciana - de "gelatinosidade" da sociedade civil (ver Gramsci, 1978, op. cit.). Para não falar do comportamento dos demais parti. dos russos de esquerda frente $a$ evohuçäo dos acontecimentos revolucionários /ver Gruppi, 1979 , op. cit. cap. VI: Estratégia e Tática na Revolução de 1917). heterodoxos, continua preservando seu papel vital frente à reprodução das condições gerais de produção capitalista (como, aliás, as experiências social-democratas das últimas décadas o têm comprovado) ${ }^{12}$.

E, assim como Marx antevira na Comuna de Paris, o embrião de uma forma nova e revolucionária de organização do poder político no sentido assinalado acima, Lenin verá na experiência dos "Soviets" algo análogo*. O mesmo ocorrendo com Gramsci em relação às "Comissôes de Fábrica" italianas do início do século.

Ora, é sabido que Gramsci ("o primeiro leninista italiano ") ${ }^{30}$ compartilha das críticas de Lenin ao reformismo da II Internacional, seguindo o autor russo na ruptura com esta que levou à criação da III Internacional, e sendo um dos fundadores do partido que passa a representar esta última tendência política na Itália (o P.C.I.), através de uma cisão no velho P.S.I., de tradição social-democrata ${ }^{76}$.

Portanto, o que queremos frisar, em primeiro lugar, é que, se a noção gramsciana de "guerra de posiçāo", a que fizemos referência acima, se distingue, por um lado, da tática política a que foram levados os bolcheviques em 17 pelas circunstâncias concretas da Rússia da época* - a "guerra de movimento" - é preciso considerar que, por outro lado, ela se distingue também, igualmente, da estratégia social-democrata de mera "ocupação" (sem "quebra") do aparelho de Estado "burguês", capitalista.

Em outros termos, o que queremos frisar é que a noção de "guerra de posição"/"democracia progressiva"/ "democracia de massas" inclui a noção marxiana-leninista de "quebra" do Estado. Com a diferença ("vis-à-vis" uma situação de "guerra de movimento") de que esta "quebra" é pensada, aqui, como algo que se realiza (tem que se realizar) anteriormente à tomada do poder político, do poder de Estado. E como condição paratal (o que, obviamente, nos obriga a trabalhar com uma concepção do Estado capitalista que năo se reduza à noção vulgar de um "comitê de negócios", de uma fortaleza a ser assaltada desde fora, mas sim com uma visão que se situe mais na direção de algo como, por exemplo, a fórmula poulantziana onde o Estado aparece como a "condensação material de uma relação de forças" ${ }^{34}$ e, portanto, como um campo possível de luta política revolucionária). 
1.2.2 - "Guerra da Posição" e "Guerra de Movimento": a questão da Luta pela Hegemonia.

Mas, além disso, a noção de "guerra de posição"/" democracia progressiva" não se reduz à questão das transformações internas ao aparelho de Estado. Uma vez que se trabalha, aqui, com a idéia, central no pensamento de Gramsci, de "Estado ampliado", onde o "Estado" é entendido, como "sociedade politica + sociedade civil", como "hegemonia revestida de coerção", etc., nas célebres formulações do autor em tela. ${ }^{27} \mathrm{E}$ onde desaparece, portanto, em primeiro lugar, a idéia de qualquer distinção essencial entre o aparelho de Estado e os "aparelhos" privados; e, em segundo lugar, entre os "aparelhos" (públicos ou privados) de hegemonia, e de coerção. Visto que todos "trabalham" igualmente, e em última instância, na mesma direção: a da "garantia das condiçôes gerais de produção", e ou "reprodução do modo de produção" (para usar, provisoriamente, conhecidas expressões althusserianas ${ }^{3}$. Ver a retomada desta discussão na seção seguinte do projeto).

$\mathrm{Ou}$, em outras palavras, todos os "aparelhos", públicos e privados, de hegemonia e de coerção são, em última análise, "Estado" (no sentido portanto, "ampliado" do termo).

E se, anteriormente, tratamos da distinção entre a noção de "democracia progressiva" e a estratégia social-democrata, nos encontramos agora no núcleo da segunda distinção que, a nosso ver, precisa ser estabelecida, entre as proposições gramsci-togliattianas e seus principais "interlocutores", ou seja, nos encontramos agora no núcleo da distinção entre "guerra de posição" e "guerra de movimento". Uma vez que, como se sabe, a primeira corresponde a uma proposição estratégica orientada para os contextos nos quais o Estado capitalista já adquiriu claramente sua forma "ampliada". Ou seja, estendeu aos "aparelhos" privados; e se tornou hegemônico, dirigente, mais do que meramente dominante e coercitivo.

Portanto, em síntese, a idéia de "guerra de posição", e sua sucedânea ("democracia progressiva") apontam, conjuntamente, no sentido da necessidade de promover, naqueles contextos, uma ação política, e ideológica (moral, cultural) ampla, que inclui, além dos problemas (por si só complexos) ligados a "quebra" do aparelho de Estado, todo o processo de luta pela hegemonia nos "aparelhos", públicos e privados, de hegemonia e de coerção* .
. 
* E as exigências de pesquisas nos obrigam a tentar promover uma tal restrição do campo temático. Mas, sendo esta restrição, em si mesma problemática, provavelmente tera que ser repensada $e$ reavaliada mais adiante.

* Ou, a rigor, reaparece. Uma vez que no passado, na fase dita "Mercantilista", anterior à constituiçäo de uma ordenação econômica de molde liberal $e$ livre-concorrencial, também estes paises viveram um periodo de for. te-intervenção estatal na vida econômica.

* - A Expressão está em Gramsci (1978 a), op. cit., nota: "O Estado", pag. 148.

* - Falamos em "mera aproximação" porque, como se sabe, o complexo processo de criação de uma sociedade absolutamente "paretiana" jamais se realizou "in totum".

\section{1 - As políticas Públicas e a "Reprodução do Modo de Produçāo".}

Como foi assinalado acima, a noção gramsciana de "Estado ampliado" nos obrigou a passar a entender o processo revolucionário, de transição para o socialismo, como abrangendo quase 0 conjunto das atividades, públicas e privadas. Mas, dentre o amplíssimo leque de questões que emergem daí, nosso interesse particular se orienta ${ }^{*}$ na direção do "subconjunto" (digamos assim) de ações "estatais" no sentido restrito do termo. Ou seja, na direção daquilo a que se convencionou chamar de "Politicas Públicas". E, mais particularmente, dentre estas, para o campo das chamadas "Politicas Sociais".

$E$ que significado tem o processo de crescente intervenção do Estado contemporâneo em diferentes setores da vida econômica e social, representado por estas, assim chamadas "policies"

É sabido que o processo histórico concreto de sua emergência e implantação adquiriu características diversas entre, por exemplo, os países que percorreram a chamada "via prussiana" (Lenin) de desenvolvimento capitalista, "vis-à-vis" os que transitaram por uma, assim chamada, "via norte-americana". ${ }^{41}$ Assim, enquanto nos primeiros a forte intervenção estatal em diferentes áreas foi um fenômeno de sempre, que acompanhou todo o processo de desenvolvimento capitalista, nos últimos ela só aparece* mais tardiamente, e na medida em que vão se tornando evidentes os problemas (econômicos e político-ideológicos) suscitados pela tentativa de estabelecimento, aí, de uma ordenação de tipo liberal "clássico", ou "ortodoxo".

Como se sabe, esta última situação pressupunha a veracidade da fórmula utilitarista, pela qual a "mão invisivel" do mercado seria capaz de levar, em última análise, à satisfação do conjunto das necessidades e interesses individuais e

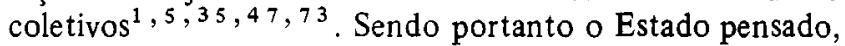
desde esta ótica, como devendo corresponder a um Estado "minimo", "policial", "veilleurde-nuit"*, restrito quase que exclusivamente à tarefa de garantir a vida e a propriedade dos cidadãos.

Mas, a mera aproximação, em alguns poucos países, a uma sociedade organizada nestas bases* - i.e., a uma sociedade paretiana, "de mercado" - ao longo do século XVIII/ XIX, parece ter sido suficiente para demonstrar as dificuldades que daí emergem do ponto de vista da própria sobrevivência da ordem (política e econômico-social) capitalista. ${ }^{65}$

Cadernos de Saúde Pública, R.J., 4(3): 360-387, out/dez, 1987. 
O que queremos frisar, portanto, até aqui, nesta seção do texto, é a idéia de que, independentemente das "vias" percorridas pelo processo de desenvolvimento capitalista em diferentes contextos, tornou-se crescentemente clara a indispensabilidade da participação estatal ativa neste processo. Participação que se realiza, em última análise, através do que se passou a chamar mais tarde de "Politicas Publicas".

O porquê desta indispensabilidade, por seu turno, é uma questão que me parece ter sido bastante bem explora$\mathrm{da}$, e resolvida, ao interior do processo (já assinalado mais acima), de retomada dos elementos para uma teoria do Estado capitalista presentes, de forma não-sistematizada, nos "clássicos" do marxismo. Processo este que vem sendo desenvolvido nos últimos anos por autores como, por exemplo, os que compõe a chamada "Teoria Derivacional do Estado" ("State-derivation theory"), como W. Müller e C. Neusüss 38,52 .

Esta corrente do pensamento político marxista alemão contemporâneo busca "derivar", da análise da economia política capitalista presente nas obras "econômicas" de maturidade de Marx, indicações para pensar o fenômeno politico da "forma e funções do Estado" capitalista*49. E, trabalhando nesta direção, tem sido capaz de explorar o papel "sobredeterminante" fundamental que o Estado capitalista precisa jogar, no sentido de garantir as "condiçōes gerais de produção", e, por esta via, as condições de "reprodução do modo de produção". Uma vez que estas “condições gerais" (econômicas e político-ideológicas) não são criadas totalmente ao nível da própria fábrica, i.e., da empresa capitalista privada individual ${ }^{* 2}$. Devendo, portanto, ser asseguradas por uma ação mais ampla, a nivel superestrutural, da qual a atuação "estatal" no sentido res. trito (i.e., as "politicas públicas") é parte importante.

Também os autores estruturalistas franceses, como Althusser ${ }^{2}$, em suas reflexões sobre o fenômeno do Estado capitalista, tomam como ponto de partida considerações semelhantes, sobre o papel "sobredeterminante" do Estado na criação das "condiçôes gerais de produção" e, por esta via, na "reprodução do modo de produção" *

Mas. apesar das indicações úteis que as formulações acima possam nos oferecer para pensar a questão do Estado capitalista, seu viés economicista e funcionalista deixa sem resposta o problema de como. concretamente, o Estado capitalista faz o que faz. Ou, em outros termos, como ele chega a assumir esta posição de uma espécie de "intelectual coletivo" das classes e fraçōes dominantes, em sua ação de defesa das "condições gerais" de "reprodução do modo de produçāo".
* Embora, como assinalam estes autores, retomando conhecidas formulações de Marx, o modo de produção capitalista (e, mais particularmente, o modo de produçāo "especificamente capitalista") tenha, por outro lado, criado uma situação absolutamente original: a de que, com ele, pe. la primeira vez na história, em funçāo da "subsunçāo real" do trabalho ao capital, a extraçäo de sobre-trabalho se resolve ao nivel da própria economia, i. e., sem a necessidade de intervençäo direta de elementos de natureza "extraeconômica". O que, como se sabe, (e estes autores ressaltam ao falar da "forma" do Estado capitalis. ta) é a base da própria possibili. dade (e necessidade) do surgimento de uma "autonomia relativa" frente à infra-estrutura, que caracteriza especificamente o Estado capitalista, frente a outras "for. mas" de Estado.

* Ver nesse sentido, a metade inicial (i. e., até a seção denomina. da "A cerca da Ideologia") do cé. lebre texto de Althusser que vem sendo referido aqui (Althusser. 1983, op. cit.).

Como se sabe, o autor em questão retoma, aí, formulaçōes já presentes em obras anteriores suas, como. 'Lire' Le Capital" Paris, Maspe. ro, 1965), e "Pour Marx" (Paris, Maspero, 1965).

-A expressão é de Jessop, op. cit. 
* Esta é uma questão complexa que, a seguir estará apenas indica. da.
Teremos, portanto, que voltar, mais adiante, a esta questão, que vem sendo tratada por outros autores dentre os citados mais acima. Mas, de qualquer forma, por enquanto, com propósitos meramente analíticos, e correndo portanto o risco de um certo esquematismo (uma vez que, como se verá a seguir, estas "múltiplas determinaçōes" com freqüência se superpõe, nas situações "concretas" que são a sua "sintese"), nos parece possivel dizer - a partir das formulações acima, e como uma primeira aproximação ao problema - que a atuação governamental, através das chamadas "politicas publicas", costuma orientar-se em pelo me. nos duas grandes direções: a da garantia de condições "econômicas", e a da garantia de condiçōes "politico-ideologicas" de reprodução da ordem estabelecida e do modo de produção a ela associado.

Assim, se tomarmos o caso que nos interessa - o das chamadas "Politicas Sociais" - poder-se-á observar neste sentido, por exemplo, a nosso ver, como as ações estatais aí enquadradas costumam estar associadas (de forma complexa, superposta, e mutável entre diferentes contextos e conjunturas) a questões se poderia esquematicamente classificar naqueles dois grandes campos*61,59.

Tendo-se como exemplo de determinações de natureza "econômica" (digamos assim), nesta área, circunstâncias como: a necessidade de garantir níveis mínimos de reprodução e manutenção da força de trabalho; o papel dos gastos públicos como "contratendência à queda tendencial da taxa de lucro"; ou as pressōes de produtores privados de determinados bens e serviços para a ampliação do mercado de seus produtos, etc. $-E$, como exemplos de determinações de natureza "político-ideológica", circunstâncias como: a necessidade de garantir níveis mínimos de aceitação da ordem política dada, pela incorporação de parte das demandas de setores subalternos; ou as pressões oriundas da "lógica" de constituição das "máquinas" politico-partidárias: idem para as pressões oriundas de interesses intraburocráticos; etc.

$\mathrm{O}$ que se pretendeu assinalar, portanto, em síntese, até aqui. nesta seção do projeto, é a idéia de que, da perspectiva da ordem estabelecida e dos interesses nela dominantes, as chamadas "Politicas Públicas" jogam um papel essencial (por caminhos múltiplos e superpostos), no sentido da manuten cão e reprodução do "status quo".

Se retornarmos, agora, a partır daí, às formulações iniciais deste texto, expostas nas suas seções anteriores, delinear-se-á então nossa preocupação básica neste trabalho, que pode ser assim formulada: como devem ser pensadas, alternativamente, as chamadas "Políticas Públicas" (e, mais 
particularmente, as "Políticas Sociais") ao interior de um projeto de "guerra de posiçâo"/"democracia progressiva"?

Ou, dito de outra forma: se as "Politicas públicas" jogam um papel que nos parece razoavelmente claro como instrumento de manutenção e reprodução da ordem política e econòmica dadas, como devem ser encaradas, alternativamente, num projeto de transformaçâo radical, revolucionária (embora "progressiva") deste quadro?

E, pelo que foi exposto nas seções anteriores, esta questão pode, desde já, ser traduzida naquilo que se nos configura, a princípio, como pelo menos dois de seus elementos principais. Ganhando com isso a seguinte formulação: como se colocam, mais concretamente, no âmbito das "Politicas Públicas", e das "politicas Sociais", as questões da "quebra do Estado", e da luta pela hegemonia?

\section{2. - Como o Estado Capitalista se torna tal (ou, "o que as classes dirigentes fazem quando elas dirigem?")}

Mas, a resposta às indagações acima exige que se vá além das explicações do tipo "ex post", tal como as assinaladas anteriormente, que apenas chamam a atenção para as consequiências finais e de longo prazo da atuação governamental (ou seja, para o seu efeito sobre a "reprodução do modo de produçāo", etc.). E exigc que se passe, dai, para a interrogação sobre como a atuação governamental obtém este resultado.

A nosso ver, diferentes autores contemporâneos, den. tre os citados mais acima - como Hirsch, Offe. Habermas, Therborn, Poulantzas, ou o próprio Althusser, e outros têm produzido férteis reflexões nesta direção. As quais de. verão ser retomadas por nós, no que se constituirá, por isso mesmo, como um dos eixos teóricos centrais da investigaçâo ora proposta (ver adiante).

Mais à frente, anteciparemos, desde já, no entanto, algumas indicações iniciais sobrc esta questão.

\section{3) "Democracia Progressiva" e Políticas Sociais}

Para concluir esta primcira parte do projeto. destinada a delimitar e precisar o problema que nos ocupa, basta apenas, agora, a nosso ver, reunir e articular as questóes básicas assinaladas às seções anteriores.

Assim, na primeira seção deste projeto ("Guerra de Posição" e "Democracia Progressiva"), partimos de uma discussão sobre estes dois conceitos, inter-relacionados, para tentar estabelecer suas distinções para com seus principais "interlocutores". Resultando dai um esforço de identificação daquilo que nos parece constituir-se como as questões Cadernos de Saúde Pública, R J., 4(3): 360-387, out/dez, 1987. 
básicas que eles aportam (ou preservam) no debate sobre o tema da transição ao socialismo:

- a questão da "quebra" do Estado (i.e., a questão da necessidade, para a transição ao socialismo, do rompimen to das características estruturais do Estado capitalista; do rompimento daquilo que o constitui como tal, como "Estado", e como "capitalista", ("burguês");

- A questão da luta pela hegemonia (i.e., a questão da necessidade, nos contextos de tipo "ocidental", do desenvolvimento de uma longa luta ideológica, moral, cultural, "de trincheiras", pela superação da hegemonia burguesa aí constituída).

$\mathrm{Na}$ segunda seção do texto, partimos de uma tentativa de delimitação da nossa área particular de interesse, ao interior da concepção necessariamente "ampliada" que, desde (pelo menos) Gramsci é preciso adotar na discussão da temática do "Estado" E esta delimitação nos levou a recortar o tema das chamadas "Politicas Públicas" (e, dentro delas, o das "Politicas Sociais"). Para, em seguida, procurar mostrar que uma articulação deste tema com as questões suscitadas anteriormente exige que se vá além de uma mera descrição das "funções" desempenhadas pelas Políticas Pú. blicas/Políticas Sociais frente à "reprodução do modo de produçāo", impondo-se a discussão sobre como, concretamente, o Estado Capitalista se constitui como tal, e, no decorrer deste processo, desempenha, tendencialmente, em última instância, e no longo prazo, estas "funçōes".

E é exatamente esta a questão que, a nosso ver, articula os dois temas (pelo que ela ocupará, como já adiantamos, posição central na investigação ora proposta)

Ou seja: perguntar-se sobre como o Estado capitalista se constitui como tal; como ele se constitui como "Estado" e como "capitalista"; como ele se constitui, em última instância, num instrumento de "reproduçāo do modo de produção"; num instrumento de garantia das "condiçôes gerais" (econômicas e político-ideológicas) de produção capitalista; como ele participa do processo de constituição e manutenção da hegemonia burguesa, etc., nos leva a poder tentar identificar aquilo que corresponderia aos pontoschave do enfrentamento da questão das Políticas Públicas/ Políticas Sociais da perspectiva da estratégia de "guerra de posição"/ "democracia progressiva". Em outras palavras, nos leva a poder tentar identificar, no que tange ao âmbito das Políticas Públicas/Políticas Sociais, em que aspectos básicos daquilo que o faz ser o que é, o Estado capitalista precisa ser "quebrado", e em que aspectos da sua participação no processo de constituição da hegemonia burguesa ele pre-

Cadernos de Saúde Pública, R.J., 4(3): 360-387, out/dez. 1987. 
cisa ser enfrentado, ao interior de uma tal estratégia de transição.

Dito de outra forma: a nosso ver, é a tentativa de resposta a estes repetidos "como?" que nos permite, talvez, fugir da camisa-de-força funcionalista das infindáveis "reproduçōes" das "reproduçóes" das "reproduçōes"... Bem como da impotência das explicações economicistas de tipo "ex post factum". Buscando, ao contrário, identificar os elementos de contradição ao interior do modo de funcionamento concreto do Estado capitalista em uma de suas áreas. Elementos estes que apontem para a possibilidade objetiva de um "devir" transformador.

\section{2a PARTE: ALGUMAS INDICAÇõES E HIPÓTESES INICLAIS}

Sem querer avançar, obviamente, desde já, no que deve corresponder aos "resultados" da investigação ora proposta, gostaríamos no entanto de deixar registrado, de forma não exaustiva, nem totalmente sistemática, aquilo que se nos apresenta, no momento, como algumas indicações iniciais de trabalho no sentido apontado acima (apenas como exemplos de eventuais linhas temáticas a explorar na investigação aqui sugerida).

\section{a) "A Administração das Crises" e a atomização da realidade}

A noção de "administração das crises" (Offe) procura dar conta do fato de que, se o Estado capitalista atua, em última instância, no sentido da "garantia das condições ge. rais de produção" (no econômico e no político-ideológico), ele não costuma fazê-lo, no entanto, através de uma ação global, permanente, e clarividente, mas sim de uma forma essencialmente reativa e tópica, como resposta a crises localizadas, no processo de acumulação e/ou na legitimidade da ordem.

A importância do tema para a nossa discussão, $€$ dada, entre outras coisas, pelo fato de que isso colabora para que as "Politicas Públicas" habitualmente promovam o que poderiamos chamar de uma "atomização" ou "fragmentação da realidade" (a começar pela tradicional divisão entre "Politica Econômica" e "Politicas Sociais"). O que corresponde a uma espécie de retradução das demandas (ou, mais freqüentemente, de sentimentos e insatisfaçôes mais ou menos difusos na sociedade, e exacerbados em situações de "crise"), e sua compartimentalizaçâ. Levando com isso a um preestabelecimento de "agendas" e de "arenas" nas quais tendem, a partir daí, a ficar confinados os debates e as reivindicações. Demarcando-se, desta forma, desde o início 
e na melhor das hipóteses, um campo possível de mudanças e se us limites.

b) A "ossatura institucional" do Estado, a seletividade estrutural, os vetos e as barganhas

$\mathrm{O}$ aparelho de Estado se apresenta como um conjunto complexo de instituições, níveis hierárquicos, normas de procedimento, etapas do chamado "processo decisório", etc. que são postos como exigências "dadas" e "neutras" de uma pretensa racionalidade burocrática (Weber?), mas que viabilizam, na prática, uma série de deslocamentos, atrasos, retraduções, bloqueios, não-respostas, não-decisões, não-implementações, etc. E as noções de "ossatura institucional" do Estado, em Poulantzas, ou de "seletividade estrutural" em Offe, sugerem, em última análise, que isto tudo não se passa de umá forma aleatória, que corresponda exclusivamente a uma vaga e abstrata noção,senso comum, de "emperramento burocrático". Mas sim funciona como uma espécie de "filtro", com um "bias" de classe ${ }^{33}$ sobre as demandas, já previamente fragmentadas (como vimos há pouco), adaptando-as a "limites estruturais". O porquê (e o como) deste "bias" de classe precisa, no entanto, ser explorado através de noções como as que assinalaremos a seguir.

Agregue-se, de qualquer forma, a isto, o conjunto de barganhas e de vetos (Hirsch, Poulantzas) que diferentes forças de classe ou de frações introduzem neste complexo "policy-making" burocrático.

\section{c) Os "limites estruturais"}

De qualquer maneira, a atuação do Estado capitalista se passa dentro de limites intransponíveis (da perspectiva da ordem estabelecida), limites estes que são demarcados, em síntese, por circunstâncias tais como: "a dependência dos gastos estatais das rendas obtidas do excedente total criado pela economia capitalista"; "a supervisão dos aparethos ideológicos elou integradores de massa pelos aparelhos administrativo-repressivos centrais para limitar seu papel na reprodução ideológica e/ou na mediação de interesses dentro de limites controláveis"; etc. ${ }^{38}$

d) 0 "interesse na estabilidade" dos "grupos reinantes".

A noção de "interesse' na estabilidade" dos "grupos rinantes" ${ }^{33}$, procura explorar, na linha do que temos discutido neste projeto, o fato de que estes grupos (i.e., a burocracia governamental e os políticos profissionais) terminam por ter, objetivamente, um forte interesse na manutenção dos mecanismos e procedimentos estabelecidos, tan- 
to de acumulação, quanto de dominação política "burgue$s a$ ", "como uma precondição básica da sua própria reprodu. ção como pessoas vivendo da política" 38 . Vendo, Hirsch, nesta questão, um dos caminhos pelos quais o Estado capitalista se torna tal, na forma específica, complexa, não mecânica, pela qual isto se dá.

Aliás, esta formulação, a nosso ver, aproxima, de certa forma, Hirsch, de teóricos políticos liberais contemporâneos, como os chamados "elitistas", e também os "pluralistas" (naquilo que estas duas correntes, apesar de conflitantes, têm em comum) $)^{6,19,20,51,56,63,64,72,83}$. Ou, ainda, das discussões de Weber sobre a burocracia; e, de Weber e Michells, sobre os partidos políticos e os chamados "politicos profissionais" $50,80,81,82$. Quase não é preciso acrescentar, no entanto, que isto, obviamente, não diminui em nada o interesse do conceito hirschiano em tela, para a nossa discussão. Sendo interessante explorar suas relações com os autores supracitados.

e) A "estatolatria", o "corporativismo dos funcionários" e o "transformismo".

Além do que foi discutido no item anterior, mesmo setores ditos "progressistas" da tecnoburocacia governa. mental (i. e., que vêem a si próprios como aliados, ou como porta-vozes de interesses de se tores subalternos da sociedade civil) com freqüência, pela sua mera inserção institucional, são levados a incorporar aspectos essenciais da "logica" de funcionamento do aparelho de Estado, tais como os que temos discutido aqui. O que os leva a cair na situação da chamada "estatolatria", ou seja, uma identificação apressada e acrítica do "estatal" com o "publico", por oposição aos interesses "pritados" 68.

Se considerarmos que a concepcão do "Fstado - Sujeito" (Poulantzas). que está, em última análise, embutida nesta identificação entre o "estutul" e o "publico", corres. ponde exatamente ao núcleo da ideologia política "burguesa" (seja nas suas matrues liberais - de tipo "contratualista". "utilitarista", "pluralista". "clitista", etc - ou em suas matrues autoritarlas - como em Hegel, ${ }^{32}$ ou Comte, ${ }^{15}$ etc. $)^{2}, 24,34,43,48,70$, o que se observa, a partir daí, é algo como se se tornasse dificil, mesmo para estes setores "progressistas". ou "orimtades na direçio dos interesses das massas populares" (Poulantzas) da burocracia, perceber-se a si mesmo como "sucitos de ideologia" (Althusser). No caso, sujcitos de uma idcologia do Estado ${ }^{68}$.

Esta questio se agrava quando, como é comum ocorrer. interesses e reivindicaçoes "corporativas" de setores do "pessual do Estudo." (Poulantzas) são confundidos 
(consciente ou inconscientemente) com reivindicações e interesses de setores subalternos da sociedade civil.

Além do mais, tudo isto estabelece uma ponte desta discussão, para com aquilo que Gramsci designava por "transformismo" (i. e., o processo de cooptação de lideranças potenciais de setores subalternos, e de seus eventuais aliados nas camadas médias e na intelectualidade, pelo bloco histórico dominante).

f) 0 "pessoal do Estado" como um dos campos de luta pela hegemonia.

A discussão do item anterior resulta, em grande medida, do fato de que boa parte do "pessoal do Estado", nas áreas de "Politicas Sociais" em particular, é representado por "intelectuais tradicionais" (como por exemplo, médicos, professores, advogados, etc.). O que gera uma situação freqüente de conflito entre os princípios ético-morais presentes na sua formação profissional, e as orientações concretas que costumam assumir estas "policies", submetidas que estão, como vimos mais acima, a múltiplas determinações de diversas ordens.

Mas, de maneira mais geral, pode-se dizer que toda a burocracia governamental surge (desde o absolutismo) a partir da oposição entre o "público" e o "privado". Oposição falsa como se sabe, fortemente ideologizada, mas que se constitui, por isso mesmo, a nosso ver, num campo de luta pela hegemonia entre as classes fundamentais da sociedade moderna e suas respectivas visōes-de-mundo. Campo de luta pela efetivação (ou não) do "público" enquanto tal; pelo dessubmetimento da atuação do Estado aos interesses de grupos privados, ou do conjunto do "bloco no poder" (Pou. lantzas), etc.

\section{g) "Participação", "Transformismo" e "Democracia de Massas"}

A idéia de "participação" das formas auto-organizadas da sociedade civil (associações de moradores, sindicatos, grupos religiosos, partidos políticos, etc.), e das formas de organização dos funcionários governamentais subalternos, no processo de formulação e implementação de Políticas Públicas, tem sido crescentemente apresentada - às vezes como uma verdadeira panacéia - para o enfrentamento da questão destas políticas de uma perspectiva que se pretende transformadora (em substituição à já desgastada idéia de "participação comunitária", até há pouco corrente em diversas áreas de Politicas Sociais). ${ }^{21}$

Mas, se esta "participação" não se fizer com consciência de todas as restriçôes anteriormente apontadas, e com a 
disposição de enfrentá-las, corre o risco de levar apenas a novas formas de cooptação ou "transformismo".

$\mathrm{E}$, com isso, retornamos ao núcleo da nossa discussão. Ou seja: à idéia de que a mera incorporação de novos (e mesmo heterodoxos) atores ao "policy-making" governamental, sem que esta incorporação se faça acompanhar de uma problematização e um enfrentamento dos temas básicos da "quebra" do Estado, e da luta pela hegemonia, apenas nos levará, na melhor das hipóteses, a repor, de uma forma modernizada e atualizada, a estratégia social-democrata de mera "ocupação" e gestão "humanizada" do Estado capitalista, com as conhecidas consequêencias políticas deste fato.

A questão que se coloca para nós é, portanto, como já assinalamos, a de como incorporar, concretamente, estes "temas básicos" (a "quebra" do Estado, e a luta pela hegemonia) no desenho teórico das formas de enfrentamento da problemática das Políticas Públicas/Políticas Sociais, da perspectiva da estratégia da "Democracia Progressiva"/ "Democracia de Massas".

Como foi dito há pouco, as questões listadas nesta última seção do proje to estão aqui colocadas apenas a tỉtulo de indicações iniciais, não exaustivas, e nem completamente desenvolvidas. Ou seja, apenas como exemplos de eventuais linhas de análise a serem percorridas pelo processo de investigação.

\section{3a PARTE: A PROPOSTA DE TRABALHO}

As formulações desenvolvidas nas seções anteriores nos levam a perceber, no momento, os "passos" que deveriam compor a investigaçāo ora proposta, da maneira que se segue (que, como se verá, sugere a possibilidade de dois "niveis", inter-relacionados, de análise):

\section{1) Um Trabalho Teórico, de Caráter Monográfico}

Que se constituiria a partir de:

a) Uma revisão da literatura sobre a questão sugerida na 1 a seção do projeto. Ou seja, sobre a temática da "Guerra de posição"/ "Democracia Progressiva", ou, em termos mais gerais, sobre a questâo das estratégias de transição para o socialismo nas condições impostas pela ordenação politica de tipo "ocidental" contem. porâneo.

Questão por si só ampla, que, como foi assinalado, ocupa posição central na reflexão política marxista desde fins do século passado. 


\section{ARTIGO}

"Nosso interesse pelo "caso" italiano em questão se prende a dois motivos:

a) o fato de que um dos protago. nistas principais do processo em tela, naquele Pais Europeu, tem sido o Part'do Comunista Italiano que, como se sabe, tem sua orientaçäo estratégica pautada em formulaçōes Gramsci-Togliattianas. 0 que nos permitiria trabalhar, neste "caso", com uma situaçäo explicitamente associada a um projeto politico que se orienta na linha de questões assinaladas an. teriormente nesta proposta de investigação. Enquanto que, no "ca. so" brasileiro, as proposiçōes ini. ciais sobre a chamada "Reformo Sanitária" partiram de um grupo politicamente mais heterogêneo de atores. Em especial componen. tes de um setor, digamos "pro. gressista" da própria tecnoburo. cracia governamental da área, $e$ alguns estudiosos do tema.

b) $A$ evidente influência sobre o "caso" brasileiro la começar pe. la importaçáo do termol das idéias da Riforma Sanitária Italiana.

Estas idéias tendo delegado a nós principalmente a partir da tradu. çẫo brasileira de livros de Giovanni Berlinguer. b) Uma revisão da discussão, presente em diversos autores citados mais acima, e pertencentes ao campo do pensamento político marxista contemporâneo, sobre a temática do Estado capitalista e da ordenação política modernos.

c) Uma revisão da literatura, mais especializada, sobre as assim chamadas "Politicas Públicas" e "Politicas Sociais" (na linha da discussão sobre suas origens históricas, determinantes da sua emergência, vias distintas de evolução, padrões diferenciais, etc.); e, finalmente,

d) Uma tentativa de articulação teórica entre estes campos problemáticos, na linha do que foi exposto mais acima.

\section{2) Estudo (s) de caso}

$\mathrm{Na}$ dependência das condições de prazo de trabalho, e de recursos; poder-se-ia pensar em estender a investigação a um plano mais "empírico". Que corresponderia, em síntese, a procurar examinar como questōes da natureza das que foram tratadas mais acima têm se apresentado em situaçôes concretas, em "casos" empiricos de Políticas Públicas.

A trabalhar nesta direção, o critério de familiaridade com o tema nos levaria, seguramente, a optar por um setor de Politica Social que corresponde ao chamado "setor saúde". E, neste caso, se nos apresentam duas vertentes de trabalho (eventualmente complementares, se visássemos um estudo comparativo, e, outra vez, na dependência das condições de prazo e de recursos).

São elas: as experiências a que se vêm designando nos últimos anos pela mesma expressão - "Reforma Sanitária" - em paises, como respectivamente, a Itália*7,8,23,78 e o Brasil.

Nos dois casos no entanto (e esta seria uma hipótese central de trabalho nesta passagem da investigação), é ne. cessário, a nosso ver, distinguir duas coisas:

a) o sentido originalmente atribuído a esta expressão pelos seus primeiros formuladores; e

b) as vicissitudes dos processos de tentativa de implementação das referidas propostas.

Assim, a nosso ver, nos dois "casos" (e apesar da ressalva presente à nota anterior), a idéia de "Reforma Sanitaria", fm sua formulaçâo original, incorpora (ainda que em graus variáveis par: cada um dos "casns") temas que têm 
o cupado posição central neste nosso projeto de investigação. Quais sejam: os temas da "quebra" ou democratizaçâo do Estado; e da luta pela hegemonia (o qual, neste âmbito, é, a nosso ver, expresso basicamente pela discussão em torno da chamada "consciência sanitária"). Daí o nosso interesse por estas experiências neste projeto.

Mas, também nos dois casos (e também em graus variáveis para cada um deles), as pressões e tentativas de implementação destas idéias têm, na nossa opinião, levado as respectivas autoridades governamentais do setor ao que se poderia descrever como um duplo movimento. Que é representado, por um lado, pela incorporação do termo "Reforma Sanitária" ao discurso oficial; ${ }^{14,16,37}$ mas, por outro pelo progressivo esforço de esvaziamento dos aspectos mais "disfuncionais" digamos assim, das referidas proposiçōes." Aspectos "disfuncionais" estes que, a nosso ver, correspondem exatamente às questôes centrais anteriormente assinaladas, neste nosso projeto. Com o que, o processo efetivo de implementação das proposições em tela tem acabado caminhando, a nosso ver, (em graus variáveis para cada uma das questões assinaladas, e para cada um dos "casos" referidos), na direção de medidas de âmbito mais restrito e "funcional". Ou seja, na direção de medidas a que se poderia chamar propriamente, de "reformistas", mais restritas a aspectos de natureza "organizacional", "técnico-administrativa", dos respectivos sistemas de atenção à saúde.

Desta forma, o estudo de um ou de ambos os "casos" acima referidos parece nos possibilitar (e agora a partir da análise de casos concretos de formulação e implementação de Políticas Públicas) a exploração de questões já suscitadas, mas acima, em termos teóricos.

Quais sejam: a questão que foi sintetizada anteriormente pela pergunta "como o Estado capitalista se torna tal?" (na forma não mecânica, não necessariamente consciente e intencional por parte de seus atores, etc., em que tal processo parece se dar); e, finalmente, a questão que se constitui, em última análise, na motivação central deste trabalho: a da complexa busca pela possibilidade de formulação de proposições setoriais de políticas públicas (e respectivos mecanismos de implementação técnica e política), que visem exatamente atingir este núcleo da "natureza de classe", digamos assim, do Estado capitalista, constituindo-se, desta forma, não como instrumentos de "reprodução" mais elaborada e sofisticada da ordem, mas como voltadas à sua transformação radical, embora "progressiva".

\section{3) Metodologia e Fontes}

No que tange à parte da investigação proposta, acima referida como "um trabalho teórico de carater monográfi-
* No caso italiano, um exemplo sintomático, e precoce, deste tipo de movimento foi descrito há pouco por G. Berlinguer, em recente conferência no Congresso do Associação Brasileira de Pós-Gra. duaçäo em Saúde Coletiva (ABRASCO).

$E$ corresponde ao fato de que, logo após a promulgação da "Lei da Reforma Sanitária" naquele Pais, o governo italiano nomeia como Ministro da Saúde (e, por. tanto, responsá vel maior pela im. plementação da lei) um membro do pequeno Partido Liberal, noto. riamente opositor de muitas das formulações centrais do projeto original.

No caso brasileiro, a sensação de esvaziamento político da "Comis. săo Nacional da Reforma Sanitá. ria" tem sido expressa por vários de seus membros, em entrevistas aos jomais e em comentários pes. soais /devendo este material ser recolhido de forma mais sistemática no decorrer da investigação ora proposta). Além disso, tem sido corrente a utilizaçäo do termo "Reforma Sanitária", por parte de autoridades governamentais da área, para apenas rebatizar antigas proposiçōes, já há muito em curso neste âmbito (em especial o programa das chamadas "Açōes Integradas de Saúde", ou a criação de "Distritos Sanitários", etc.), $e$ que tem uma abrangência muito mais restrita do que o que se pode. ria chamar de "espirito original" da idéia de Reforma Sanitária (so. bre o significado político destas "antigas" proposiçoes, ver Oliveira, 1983, op. cit. e Oliveira e Teixeira, 1986, op. cit). 
co", a metodologia a empregar corresponde, obviamente, a uma revisão e interpretação da literatura pertinente aos temas ali suscitados. Parte da qual é apresentada nas "notas" que acompanham este projeto.

No que tange ao (s) "estudo (s) de caso", empregarse-ia basicamente, além de uma revisão da literatura secundária sobre os temas em tela: a análise de documentos oficiais e dados quantitativos relativos às proposições em dis. cussão; e entrevistas dirigidas com atores significativos envolvidos nestes processos.

In the introduction, the author discusses the current debate on the "Reforma Sanitária"; a proposal to innovate health policy. The author draws attention to the different meanings that can be attributed, in his opinion, to the use of this scm in Brazil. He focusses particularly on the meaning closer to that of the Italian proposal of the same name ("Riforma Sanitaria").

The discussion leads the author to question the relationship between the characteristics of the contemporary political liberal organization and the Gramsci-Togliattian strategy of the transition in socialism, within the field of "Public Policies" and more specifically "Social Policies". The article encis with a preliminary outline a comparative inrestigation in this fiold.

\section{REFERÊNCIAS BIBLIOGRÄFICAS}

01. AIKLN, Henry O. ed. Hume's moral and political philosophy. Now York, Hiafner Press, 1948.

03. ALTHUSER, Louis. Aparelhos ideológicos de Estado. Rio de Ja. neiro, Graal, 1983.

02. ALTHUSSR: Louis. Acerea del "Contrato Social". In.: LEVY STRAUSS. C. ora. Presencia de Rousseau. Buenos Aires, Nucva Vision, 1972.

04. BENJAMIN: Horkheimer: Habermas e Adorno. Sāo Paulo, Abril Cultura, 1984. (Coleção Os Pensadores)

05. Bl:NTHAM, Jer'my. Uma introdução aos princípios da moral e da kgislação. In: BlNTHAM e Stuart Mill. São Paulo, Abrıl Cultural, 1984. (Coleção Os Pensadores)

06. BINTLIYY, Arthur. The process of government. Cambridge, The Be.lknap Press, 1967

07. BI:RLINGUler, (juvanni. Medicina e politica. São Paulo, CEBHS/HUCYTLC, 1978.

08. Bt RLINGUl:R, Giovanni. Saúde nas fábricas. São Paulo, CEIIS/HUCITEC, 1983.

09. BOBB!O, Norburto org. O ronc, is, in socieunde civil. R10 de banciro, Graal. 1982. 
10. BOBBIO, Norberto org. O marxismo e o estado. Rio de Janeiro, Graal, 1979.

11. BUCCI-GLUCKSMAN, Cristine. Gramsci e o Estado. Rio de Janero, Paz e Terra, 1980.

12. BUCCI-GLUCKSMAN, Cristine \& THERBORN, Soran. Le défi social-democrate. Paris, Maspero, 1981.

13. COHN, Gabriel org. Theodor Adorn. São Paulo, Ática, 1986.

14. COMISSÃO Nacional da Reforma Sanitária. Súmula (15) dez. 1986.

15. COMTE, Auguste. Discurso sobre o espírito positivo. In: COMTE. São Paulo, A bril Cultural, 1978. (Coleção Os Pensadores)

16. CONFERENCIA NACIONAL DE SAÚDE, 8. Brasilia, 17-21 março 1986. Relatório final. Brasília, 1986.

17. Coutinho, Carlos Nelson. Gramsci. Porto Alegre, L \& PM, 1981.

18. COUTINHO, Carlos Nelson. Introdução a Togliatti. In - -. A democracia como valor universal e outros ensaios. 2. ed. Rio de Janeiro, Salamandra, 1984.

19. DAHL, Robert. Dillemas of pluralistic democracy. New Haven, Yale University Press, 1982.

20. DAHL, Robert. A preface to democratic theory. Chicago, The University of Chicago Press, 1986.

21. DONNANGE LO, Maria Cecilia F. Saúde e sociedade. São Paulo, Duas Cidades, 1976.

22. ENGELS, Friedrich. Introducción (1895). In: MARX, Karl. Las luchas de clase en Francia de 1848 e 1850. Buenos Aires, A teneo, 1973.

23. GARYSZEWSKI, V. Reorganização dos serviços de saúde na Itália e algumas reflexóes sobre a experiência brasileira. Rio de Janeiro, 1985. (Dissertação de Mestrado - ENSP/FIOCRUZ).

24. GERRATANA, Valentino. Rousseau y Marx. In: -... Investiga. ciones sobre la historia del marxismo. Barcelona, Grijalbo, 1975.

25. GRAMSCI, Antonio. Concep̧ão dialética da história. Rio de Janeıro, Civilização Brasileira, 1980.

26. GRAMSCI, Antonio. Os intelectuais e a organizaçāo da cultura. Rio de Janeiro, Civilização Brasileira, 1978.

27. GRAMSCI, Antonio Maquiavel, a politica e o Estado moderno. Rio de Janerro, Civilização Brasileira, 1978.

28. GRUPPI, Luciano. O conceito de hegemonia em Gramsci. Rio de Janeiro, Graal, 1978.

29. GRUPPI, Luciano. A guerra, a soclal-democracia, o imperialismo. In: -... O pensamento de Lenin. Rio de Janerro, Graal, 1979. cap. 5.

30. GRUPPI, Luclano. Tudo começou com Maquiavel as concepções de Estado em Mrr. Engels, Len in c Gramscr, Porto Alegre, L \&PM, 1980. pL. ?

31. HABERMAS, Juergen. A crise de legitmação no capitalismo tar. dio. Rio de Janeiro, Tempo Brasileiro, 1980.

32. HEGEL, Georg W. F. Principios da filosofia do direito. Lisboa, Guimarães, 1986.

33. HIRSCH, Joachım. Obser açoes teóricas subre o Estado burgués e sua crise. In: POLLANTZAS, Nicos org. O Estado em crise. Rio de Janeiro, Graal, 1977.

34. HOBBES, Thomas. Leviatã. In HOBBI:S. São Paulo, Abril Cultural, 1979. (Coleção Os P': nciadores)

35. HUME, David. Ensaios murais. politicns l lteráros. In: BL RKLLEY a Hume. São Patí. Abril Cultural, 1984 (Cokçũo OS Pensador's)

Cadernos de Saúde Pública, R.J., 4(3):360-387, out/dez, 1987. 
36. INGRAO, Pietro. As Massas e o poder. Rio de Janeiro, Civilização Brasileira, 1980.

37. ITALIA. Camera dei Deputati. Instituzione del servizio sanitário nazionale. Roma, 1979.

38. JESSOP, Bob. Form and functions of the State. In: The capitalist State: marxist and methods. Oxford, Martin Robertson, 1982, cap. 3

39. KOTHE, Flávio R. org. Walter Benjamin. São Paulo, Ática, 1985

40. LENIN, Vladimir I. Ulianov. O Estado e a revolução. São Paulo, HUCITEC, 1978.

41. LENIN, Vladimir I. Ulianov. O programa agrário da social democracio. Sāo Paulo, HUCITEC, 1980.

42. LENIN, Vladimir I. Ulianov. Que fazer? São Paulo, Alfa-Omega, 1979.

43. LOCKE, John. Segundo tratado de governo. In LOCKE. São Paulo, Abril Cultural, 1983. (Coleção Os Pensadores)

44. LUXEMBURG, Rosa. Reforme ou revolução. São Paulo, Global, 1986.

45. LUXEMBURG, Rosa. Rosa Luxemburg. São Paulo, Nova Cultural, 1985.

46. MACCICOCHI, Maria-Antonieta. A favor de Gramsci. Rio de Janeiro, Paz e Terra, 1977.

47. MCPHERSON, C. B. A democracia liberal: origens e evolução. Rio de Janeiro, Zahar, 1978. cap. 2.

48. MCPHERSON, C. B. A teoria politica do individualismo posses. sivo. Rio de Janeiro, Paz e Terra, 1979.

49. MARX, Karl. O Capital. São Paulo, Ciências Humanas, 1978. cap. 6.

50. MICHELLES, Robert. Partidos politicos. Brasília, UnB, 1980.

51. MOSCA, Caetano. La classe politica. Roma, Laterza, 1975.

52. MƯLLER, Wolfang \& NEUSUSS, Cristel. The welfare-state illusion and the contradiction between wage labour and capital. In: HOLLOWAY, John \& PICCIOTTO, Sol. State and capital: a marxist debate. London, Edward Arnold Publ., 1978.

53. MUN̄OZ, Gabriel. Introducción. In: LUXEMBURG, Rosa. Escritos politicos. Barcelona, Grijalgo, 1977.

54. NAPOLITANO, Giorgio. O partido comunista italiano, $O$ socialismo e a democracia. São Paulo, Ciências Humanas, 1979.

55. NEGT, Oscar. O marxismo e a teoria da revolução no último Engels. In: HOBSBAWN, Eric J. org. História do marxismo. Rio de Janeiro, Paz e Terra, 1985. v. 2.

56. NICHOLLS, David. Three varieties of pluralism. London, The MacMillan Press, 1974.

57. OFFE, Claus. Dominaçāo política e estruturas de classe: contribuição à análise dos sistemas sociais do capitalismo tardio. In: WOGT, Winfried et alii. Estado e capitalismo. Rio de Janeiro, Tempo Brasileiro, 1980.

58. OFFE, Claus. Problemas estruturais do Estado capitalista. Rio de Janeiro, Tempo Brasileiro, 1984.

59. OLIVEIRA, Jaime A. listado, sociedade e políticas na periferia. In: - -. Interesses sociais e mecanismos de apresentaçāo: a política de saúde no Brasıl. pós-64. Rio de Janeiro, ENSP, 1983. Seção 2.1.

60. OLIVEIRA, Jaime A. Interesses sociais e mecanismos de apresentaçăo: a política de saúde no Brasil pós-64. Rio de Janeiro, ENSP, 1983. $174 \mathrm{p}$.

61. OLIVEIRA, Jaime A. Política social, acumulação e legitimidade. R. Admin. públ., 18 (2) abr./jun. 1984.

Cadernos de Saúde Pública, R.J., 4(3): 360-387, out/dez, 1987. 
62. OLIVEIRA, Jaime A. \&TEIXEIRA, Sonia M. F. (Im) Previdência social: 60 anos de história da previdência no Brasil. Rio de Janeiro, Vozes, 1986.

63. PARETO, Vilfredo. Pareto. São Paulo, Ática, 1984.

64. PARETO, Vilfredo. Sociological writings.

65. POLANYI, Karl. A grande transformação. Rio de Janeiro, Campus, 1980.

66. PORTELLI, Hugues. Gramsci e o bloco histórico. Rio de Janeiro, Paz e Terra, 1977.

67. POULANTZS, Nicos. A crise das ditaduras. Rio de Janeiro, Paz e Terra, 1976.

68. POULANTZAS, Nicos. O estado, o poder, o socialismo. Rio de Janeiro, Graal, 1980.

69. POULANTZAS, Nicos. Poder politico e classes sociais do estado capitalista. Porto, Portucalense, 1974.

70. ROUSSEAU, Jean-Jacques. Do contrato social:. In: ROUSSEAU. São Paulo, Abril Cultural, 1983. (Coleçāo Os Professores).

71. SASSOON, Donald. Introduction. In: TOGLIATTI, Palmiro. On Gramsci and other writings. London, Lawrence and Wishart, 1979.

72. SCHUMPETER, Joseph. Capitalismo, socialismo e democracia. Rio de Janeiro, Fundo de Cultura, s. d. cap. 21-23.

73. SMITH, Adam. Theory of moral sentiments.

74. THERBORN, Goran. The ideology of power and the power ideology. London, NLB, 1980.

75. THERBORN, Göran. What does the rulling classes do when it rules? London, NLB, 1978.

76. TOGLIATTI, Palmiro. Socialismo e democracia. Rio de Janeiro, Muro, 1980.

77. TOGLIATTI, Palmiro. Liçōes sobre o fascimo. São Paulo, Ciências Humanas, 1978.

78. UMA REVOLUÇÃO na saúde. Tribune da Imprensa, 10 fevereiro 1987.

79. VICENT, Jean-Marie. O estado em crise. In: POULANTZAS, Nicos org. O Estado em crise. Rio de Janeiro, Graal, 1977.

80. WEBER, Max. Burocracia. In: --. Ensaios de sociologia. Rio de Janeiro, Zahar, 1979.

81. WEBER, Max. La institución estatal racional y los partidos políticos y parlamentos modernos: sociologia del estado. In:-Economia y sociedad. México, Fondo de Cultura, 1969.

82. WEBER, Max. Parlamentarismo e governo numa Alemanha reconstruída. In: WEBER. São Paulo, Abril Cultural, 1980. (Coleção Os Pensadores). •

83. WRIGHT, Milss C. A elite do poder. Rio de Janeiro, Zahar, 1975 . 